\title{
Jarak antara Saraf Femoralis dan Arteri Femoralis pada Daerah Lipat Inguinal Orang Dewasa dengan Menggunakan Pencitraan Ultrasonografi untuk Panduan Letak Penyuntikan Blokade Saraf Femoralis
}

\author{
Nur Intan Nasution, ${ }^{1}$ Dedi Fitri Yadi, ${ }^{2}$ A. Muthalib Nawawi ${ }^{2}$ \\ ${ }^{1}$ Rumah Sakit Umum Daerah Cibabat Cimahi, ${ }^{2}$ Departemen Anestesiologi dan Terapi Intensif \\ Fakultas Kedokteran Universitas Padjadjaran/Rumah Sakit Dr. Hasan Sadikin Bandung
}

\begin{abstract}
Abstrak
Blokade saraf femoralis merupakan salah satu metode blokade saraf perifer yang digunakan untuk memfasilitasi operasi ekstremitas bawah. Blokade femoralis memiliki efek analgesia perioperatif yang efektif dengan sedikit efek samping sistemik, penurunan kebutuhan opioid serta mobilisasi lebih awal dan murah. Arteri femoralis digunakan sebagai penanda anatomis pada blokade saraf femoralis karena letaknya berdekatan dengan saraf femoralis. Penelitian ini bertujuan mengetahui jarak titik tengah saraf femoralis terhadap titik tengah arteri femoralis di daerah lipatan inguinal orang dewasa menggunakan pencitraan ultrasonografi untuk membantu keberhasilan blokade saraf femoralis. Metode penelitian adalah deskriptif analisis. Penelitian dilakukan terhadap 43 subjek sukarelawan berusia 18-60 tahun dengan indeks massa tubuh normal. Penelitian telah dilakukan bulan September-Oktober 2014 di Departemen Anestesiologi dan Terapi Intensif Fakultas Kedokteran Unpad dan Central Operating Theatre (COT) lantai 4 Rumah Sakit Dr. Hasan Sadikin Bandung. Analisis data menggunakan Uji Mann-Whitney dan uji t. Hasil penelitian, jarak ratarata titik tengah arteri femoralis terhadap titik tengah saraf femoralis pada laki-laki 1,075 $\pm 0,13 \mathrm{~cm}$ dan pada perempuan $1,069 \pm 0,13 \mathrm{~cm}$. Simpulan penelitian, jarak arteri femoralis dan saraf femoralis $1,07 \mathrm{~cm}$ lateral terhadap arteri femoralis.
\end{abstract}

Kata kunci: Blokade saraf femoralis, saraf femoralis, ultrasonografi

\section{Distance between Femoral Nerve and the Femoral Artery at the Level of Inguinal Crease with Ultrasound as a Guid for Femoral Nerve Block Injection}

\begin{abstract}
The femoral nerve block is one the peripheral nerve block methods that are used to falicitate lower extremity surgical procedures. The advantages of femoral nerve block include an effective perioperative analgesia with minimum systemic side effects, lower dosage of opioids, early mobilization and cost effective. This study aimed to measure the distance from the mid point of the femoral nerve to the mid point of the femoral artery at the level of inguinal crease of adults with ultrasound guidance that will determine the success rate of femoral nerve block. A descriptive analytic study involving 43 volunteer subjects aged 18-60 years was performed at the Anesthesiology and Intensive Care Department of the Faculty of Medicine, Universitas Padjadjaran and Central Operating Theatre (COT) of Dr. Hasan Sadikin General Hospital Bandung between September and October 2014. Statistical analysis are using Mann-Whitney test and independent t-test. Results showed that the average distance from the mid point of the femoral nerve to the mid point of the femoral artery in male was $1.075 \pm 0.13 \mathrm{~cm}$ and in female was $1.069 \pm 0.13 \mathrm{~cm}$. This study conclude that the average distance of femoral artery to the femoral nerve is $1.07 \mathrm{~cm}$ lateral to the femoral artery.
\end{abstract}

Key words: Femoral nerve, femoral nerve block, ultrasonography

Korespondensi: Nur Intan Nasution, dr., SpAn, Rumah Sakit Umum Daerah Cibabat Cimahi, Jl. Jend. Amirmachmud No. 140 Cimahi 40253, Tlp 021-8617115, Faks 022-2038306, Mobile 081218383094,Email intan_nasution@yahoo.com 


\section{Pendahuluan}

Blokade saraf femoralis merupakan salah satu metode blokade saraf perifer yang sering dipergunakan untuk pembedahan ekstremitas bawah. Prinsip blokade saraf perifer adalah menyuntikkan sejumlah obat anestesi lokal di sekitar saraf atau kompartemen yang berisi saraf sehingga terjadi blokade konduksi saraf untuk jangka waktu sementara, yaitu 2-24 jam bergantung pada jenis serta jumlah anestetik lokal yang digunakan. ${ }^{1}$ Blokade saraf femoralis digunakan untuk memfasilitasi pembedahan pada daerah femur bagian anterior, lutut, dan medial ekstremitas bawah. ${ }^{1,2}$

Keuntungan teknik blokade saraf femoralis adalah menghasilkan relaksasi otot yang baik selama operasi, efek analgesia pascaoperasi, penurunan jumlah kebutuhan analgetik opioid intravena, hemodinamik lebih stabil, efisiensi waktu dalam ruang operasi, mengurangi waktu di ruang pemulihan, mobilisasi lebih awal dan rehabilitasi yang lebih cepat, serta biaya yang lebih rendah. Blokade saraf femoralis merupakan teknik anestesi yang tepat untuk pasien yang bermasalah dengan mual muntah pascaoperasi serta pasien dengan risiko tinggi untuk dilakukan anestesi umum. ${ }^{3-5}$

Keuntungan paling signifikan dari blokade saraf femoralis untuk operasi pada ekstremitas bawah adalah efek analgesia perioperatif yang sangat efektif dengan sedikit efek samping sistemik. Terdapat bukti yang menunjukkan bahwa blokade saraf femoralis bila dibanding dengan analgesia sistemik, dapat memberikan analgesia yang lebih cepat, serta mengurangi kebutuhan opioid dengan efek samping yang lebih rendah seperti mual, muntah, hipotensi, konstipasi, dan depresi napas terutama pada geriatri. ${ }^{3,4,6}$

Penting bagi para praktisi untukmengetahui karakteristik anatomi saraf femoralis dan juga arteri femoralis di inguinal dalam melakukan blokade saraf femoralis karena menentukan tingkat keberhasilan blokade saraf femoralis. Letak/posisi saraf femoralis di lipatan inguinal berdekatan dengan letak arteri femoralis yang dapat dengan mudah diidentifikasi dengan cara melakukan palpasi ataupun mempergunakan alat stimulasi saraf perifer, serta dapat pula dengan visualisasi saraf femoralis dan arteri femoralis memakai pencitraan ultrasonografi. ${ }^{7}$

Penyuntikan saraf femoralis secara buta/ blind dilakukan dengan menggunakan penanda anatomis arteri femoralis sebagai panduan penyuntikan yang dilakukan dengan posisi berbaring terlentang di tempat tiduryang datar dan kedua kaki lurus. Jarum disuntikkan pada lipatan inguinal 1-2 cm lateral terhadap arteri femoralis dengan arah $90^{\circ}$ dengan kedalaman jarum kurang lebih $3 \mathrm{~cm}$. Keadaan parestesia terjadi jika pasien merasakan sensasi seperti kesemutan atau sengatan listrik yang muncul ketika jarum menyentuh saraf femoralis, jarum kemudian ditarik secara perlahan. Anestetik lokal kemudian dimasukkan di area sekeliling saraf femoralis. Kelemahan teknik parestesia adalah peningkatan risiko kerusakan saraf serta menimbulkan rasa tidak nyaman untuk beberapa pasien. ${ }^{2,8}$

Stimulasi saraf menggunakan alat stimulasi saraf perifer dapat menunjukkan lokasi saraf yang akan diblokade dengan cara memberikan arus listrik searah yang dihubungkan dengan insulated needle sehingga akan didapatkan respons motorik, dengan arus yang semakin kecil menunjukkan posisi yang semakin dekat dengan saraf femoralis. Respons motorik yang terjadi pada blokade saraf femoralis adalah kontraksi otot kuadriseps. Respons motorik yang sesuai dengan saraf femoralis terbukti meningkatkan angka keberhasilan blokade saraf perifer. ${ }^{2,8}$

Pada penelitian jarak antara saraf femoralis dan arteri femoralis menunjukkan hasil bahwa lokasi penyuntikan dalam rangka blokade saraf femoralis yang dilakukan pada jarak $1,87 \pm 0,1 \mathrm{~cm}$ lateral terhadap arteri femoralis pada daerah lipatan inguinal, akan membuat blokade saraf femoralis menjadi lebih mudah dan lebih cepat dilakukan dibanding dengan penanda anatomis konvensional, yaitu $1-2 \mathrm{~cm}$ lateral terhadap arteri femoralis. ${ }^{9}$

Hasil penelitian lainnya menyatakan bahwa letak penyuntikan pada metode blokade saraf femoralis pada daerah lipatan inguinal, yaitu daerah lipatan kulit yang terletak 4 hingga 6 $\mathrm{cm}$ di bawah ligamentum inguinal ternyata 
akan menghasilkan frekuensi tertinggi dalam hal kontak antara jarum dan saraf femoralis (71\%) dibanding dengan penyuntikan yang dilakukan pada daerah ligamentum inguinal, yaitu pada daerah antara spina iliaka anterior superior dan medial tuberkel pubis. Penelitian tersebut juga menemukan bahwa pada daerah lipatan inguinal, saraf femoralis berukuran lebih besar serta jaraknya lebih dekat ke fasia lata secara bermakna. ${ }^{10}$

Teknologi pencitraan ultrasonografi (USG) mulai banyak dipergunakan oleh para praktisi dalam melakukan penatalaksanaan anestesia regional karena dapat memberikan gambaran struktur anatomi saraf perifer sehingga akan meningkatkan akurasi dan juga menurunkan komplikasi. Karakteristik saraf perifer pada pencitraan ultrasonografi akan memberikan gambaran seperti sarang tawon yang terbentuk oleh jaringan ikat serta serabut saraf. ${ }^{11}$

Saat ini, di Indonesia belum ada publikasi tentang jarak antara saraf femoralis dan arteri femoralis pada orang dewasa yang penting sekali sebagai panduan untuk penentuan letak penyuntikan blokade saraf femoralis sehingga blokade saraf femoralis yang dilakukan secara blind diharapkan lebih akurat dan komplikasi dapat dihindarkan. Selain itu, alat stimulasi saraf perifer dapat membantu mengetahui lokasi penyuntikan dengan tepat.

Penelitian ini bertujuan mengetahui jarak titik tengah saraf femoralis terhadap titik tengah arteri femoralis pada daerah lipatan inguinal orang dewasa memakai pencitraan ultrasonografi untuk membantu keberhasilan blokade saraf femoralis.

\section{Subjek dan Metode}

Penelitian ini merupakan penelitian deskriptif analisis yang dilakukan terhadap 43 subjek sukarelawan yang terdiri atas beberapa residen Departemen Anestesiologi dan Terapi Intensif Fakultas Kedokteran Universitas Padjadjaran (Unpad) dan juga penata anestesia di Rumah Sakit Dr. Hasan Sadikin (RSHS) Bandung. Penelitian dilakukan di RSHS Bandung pada periode bulan September-Oktober 2014.

Kriteria inklusi pada penelitian ini adalah sukarelawan berusia 18-60 tahun dengan indeks massa tubuh normal. Kriteria eksklusi adalah kelainan anatomi ekstremitas bawah serta kelainan anatomi panggul. Besar sampel minimal ditentukan berdasarkan rumus besar sampel untuk data numerik, sampel tunggal untuk perkiraan rata-rata dengan ketepatan absolut dan didapatkan bahwa jumlah sampel minimal adalah 35, pada penelitian ini jumlah sampel yang berhasil dikumpulkan adalah 43 sampel.

Setelah mendapatkan persetujuan Komite Etik Penelitian Kesehatan RSHS Bandung, subjek penelitian diberikan penjelasan tentang tujuan, kegunaan, serta tata cara pelaksanaan penelitian terhadap subjek yang telah setuju dan menandatangani surat persetujuan untuk ikut penelitian (informed consent). Kemudian, dilakukan pencatatan data umum, pengukuran tinggi badan serta berat badan dalam posisi berdiri. Subjek penelitian dibaringkan pada tempat tidur yang datar dengan posisi tubuh terlentang dengan kedua kaki lurus. Daerah lipatan inguinal yaitu lipatan kulit yang terletak 4-6 cm di bawah ligamentum inguinal ditandai mempergunakan pensil pewarna. Gel ultrasonografi diaplikasikan pada probe dan diletakkan di daerah lipatan inguinal untuk mencari gambaran saraf femoralis dan arteri femoralis.

Pencitraan ultrasonografi (USG) kemudian dilakukan dengan memakai USG Sonosite ${ }^{\circledR}$ linear probe 6-13 MHz. Probe diletakkan pada posisi sejajar dengan lipatan inguinal dan dilakukan penentuan diameter arteri femoralis sehingga berpotongan $90^{\circ}$. Titik perpotongan dinyatakan sebagai titiktengah arteri femoralis, kemudian dilakukan juga penentuan diameter saraf femoralis sehingga berpotongan $90^{\circ}$. Titik perpotongan ini dinyatakan sebagai titik tengah saraf femoralis. Penentuan jarak antara arteri femoralis dan saraf femoralis adalah dengan proyeksi titik tengah arteri femoralis dan saraf femoralis secara vertikal, kemudian diukur menggunakan penggaris dengan skala sesuai jarak hasil pencitraan ultrasonografi dalam satuan sentimeter.

Analisis jarak antara saraf femoralis dan arteri femoralis dilakukan dengan Uji Mann- 


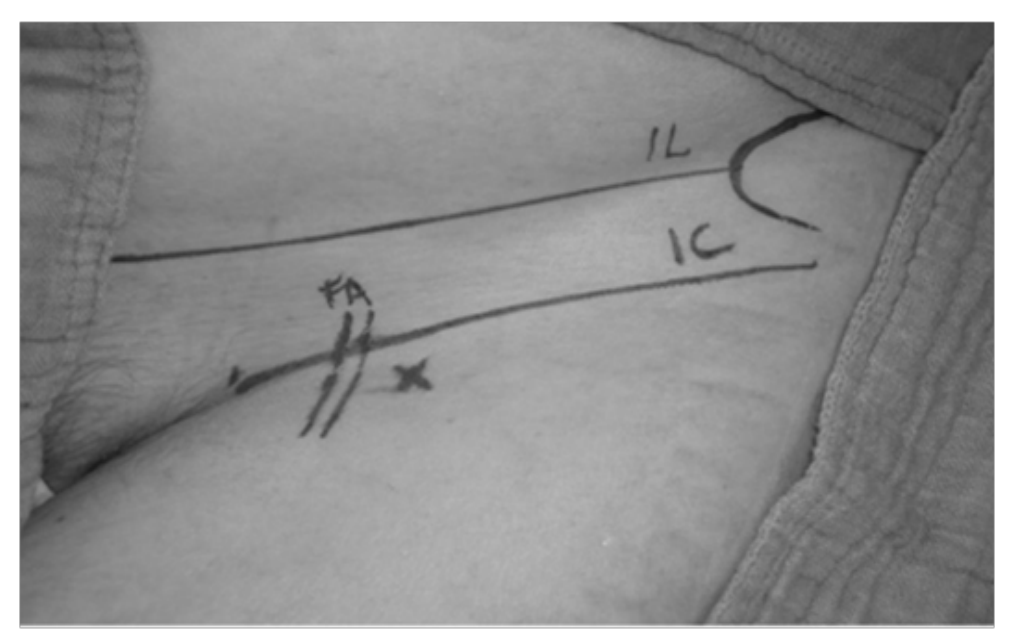

Gambar 1 Penanda Anatomis Blokade Saraf Femoralis, IL: Ligamentum Inguinal, IC: Lipatan Inguinal, FA: Arteri Femoralis

Sumber: Hadzic ${ }^{12}$

Whitney serta uji-t. Nilai p bermakna secara statistika bila $\mathrm{p}<0,05$. Analisis data penelitian ini menggunakan program statistical product and service solution (SPSS) for windows version 20.0

\section{Hasil}

Penelitian ini dilakukan pada 43 sukarelawan terdiri atas laki-laki sebanyak 22 orang (51\%) dan perempuan 21 orang (49\%). Karakteristik umum subjek penelitian, secara perhitungan statistika menggambarkan bahwa terdapat perbedaan yang signifikan pada variabel tinggi badan, berat badan, serta indeks massa tubuh dengan nilai $\mathrm{p}<0,05$ baik untuk jenis kelamin laki-laki maupun perempuan. Variabel usia secara statistika tidak terdapat perbedaan signifikan dengan nilai $\mathrm{p}=0,835$ baik untuk jenis kelamin laki-laki maupun perempuan (Tabel 1).

Hasil uji normalitas menggunakan Shapiro-

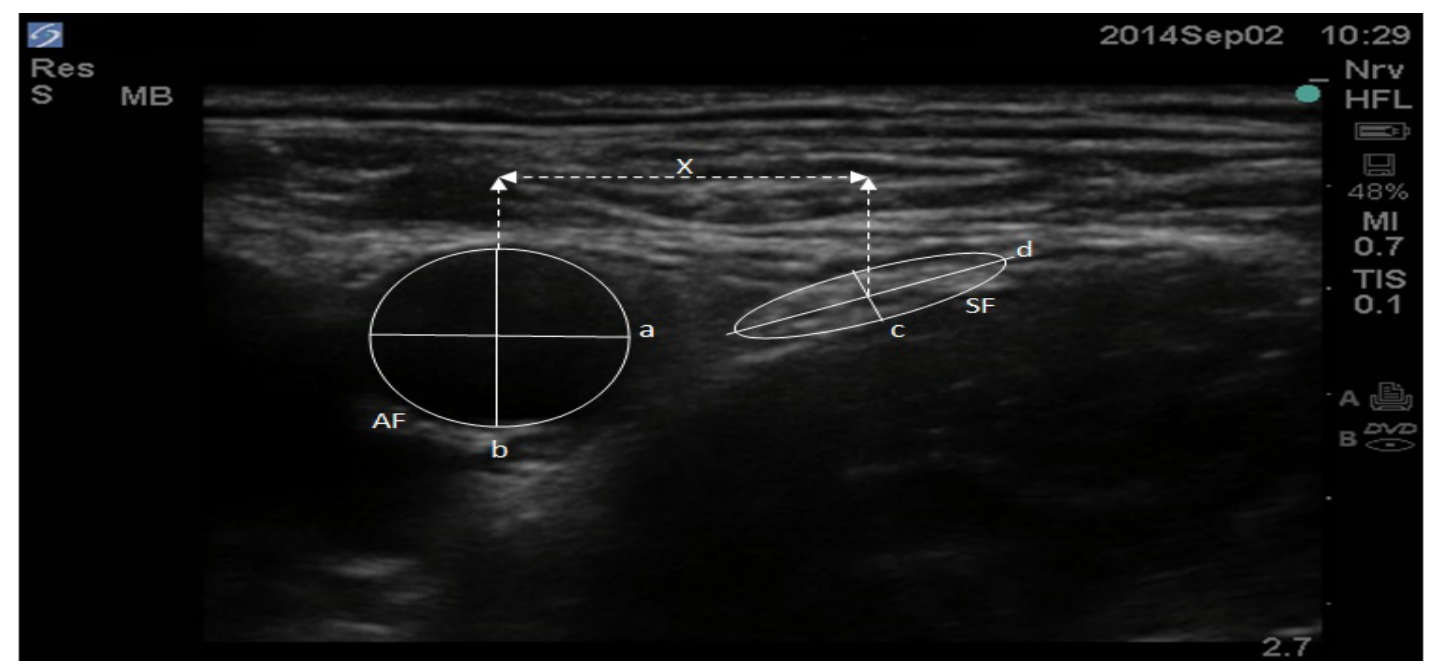

Gambar 2 Pengukuran Jarak antara Arteri Femoralis dan Saraf Femoralis, AF: Arteri Femoralis, a dan b: Diameter Arteri Femoralis, SF: Saraf Femoralis, c dan d: Diameter Saraf Femoralis, X: Proyeksi Jarak antara Titik Tengah Arteri Femoralis dan Titik Tengah Saraf Femoralis 
Tabel 1 Karakteristik Umum Subjek Penelitian

\begin{tabular}{lccc}
\hline \multirow{2}{*}{ Karakteristik Subjek Penelitian } & \multicolumn{2}{c}{ Jenis Kelamin } & \multirow{2}{*}{ Nilai p } \\
\cline { 2 - 3 } & Laki-Laki & Perempuan & \\
\hline Jumlah & 22 & 21 & \\
Usia (tahun) & & & $0.835^{*}$ \\
$\quad$ Rata-rata & 31,77 & 32,57 & \\
$\quad$ Rentang & $26-38$ & $26-49$ & \\
Tinggi badan (cm) & & & $0.000^{* *}$ \\
$\quad$ Rata-rata & 168,82 & 160,86 & \\
$\quad$ Rentang & $157-180$ & $150-170$ & \\
Berat badan (kg) & & & $0.000^{* *}$ \\
$\quad$ Rata-rata & 65,14 & 56,19 & \\
$\quad$ Rentang & $50-78$ & $43-70$ & \\
IMT (kg/m ${ }^{2}$ ) & & & $0.05^{* *}$ \\
$\quad$ Rata-rata & 22,81 & 21,66 & \\
$\quad$ Rentang & $19-25$ & $19-25$ & \\
\hline
\end{tabular}

Keterangan: $\left({ }^{*}\right)$ nilai p berdasarkan uji-t

$\left.{ }^{* *}\right)$ nilai $\mathrm{p}$ berdasarkan Uji Mann-Whitney. Nilai p bermakna $(\mathrm{p}<0,05)$

Wilk menunjukkan bahwa tidak semua data penelitian ini memiliki distribusi yang normal. Data yang memiliki distribusi normal adalah variabel tinggi badan, berat badan, dan juga indeks massa tubuh dengan nilai $p>0,05$ baik untuk jenis kelamin laki-laki maupun jenis kelamin perempuan. Varibel usia, jarak antara arteri femoralis dan saraf femoralis memiliki distribusi tidak normal dengan nilai $\mathrm{p}<0,05$ baik untuk kelompok laki-laki maupun perempuan (Tabel 2).

Jarak arteri femoralis dengan saraf femoralis rata-rata pada laki-laki dari hasil pencitraan ultrasonografi adalah 1,075 $\pm 0,13 \mathrm{~cm}$. Jarak antara arteri femoralis dan saraf femoralis rata-rata pada perempuan $1,07 \pm 0,13 \mathrm{~cm}$. Hal

Tabel 2 Uji Normalitas

\begin{tabular}{llccc}
\hline \multirow{2}{*}{ Variabel } & \multirow{2}{*}{ Jenis Kelamin } & \multicolumn{3}{c}{ Shapiro-Wilk } \\
\cline { 3 - 5 } & & Statistik & Jumlah & Nilai p \\
\hline \multirow{2}{*}{ Usia } & Laki-Laki & 0,975 & 22 & 0,828 \\
\multirow{3}{*}{ Tinggi badan } & Perempuan & 0,840 & 21 & 0,003 \\
& Laki-Laki & 0,964 & 22 & 0,571 \\
Berat badan & Perempuan & 0,973 & 21 & 0,797 \\
& Laki-Laki & 0,985 & 22 & 0,972 \\
Indeks massa tubuh & Perempuan & 0,953 & 21 & 0,391 \\
& Laki-Laki & 0,927 & 22 & 0,105 \\
Jarak saraf femoralis dengan arteri & Perempuan & 0,938 & 21 & 0,195 \\
femoralis & Laki-Laki & 0,843 & 44 & 0,014 \\
& Perempuan & 0,931 & 42 & 0,015 \\
\hline
\end{tabular}

Keterangan: nilai p>0,05 menunjukkan distribusi data normal, nilai $p<0,05$ menunjukkan distribusi data tidak normal 
Tabel 3 Jarak Arteri Femoralis dengan Saraf Femoralis

\begin{tabular}{lccc}
\hline \multicolumn{1}{c}{ Variabel } & Laki-Laki & Perempuan & Nilai p \\
\hline Jumlah & 44 & 42 & \\
Jarak arteri femoralis dan saraf femoralis $(\mathrm{cm})$ & & & $0,830^{* *}$ \\
$\quad$ Rata-rata & 1,075 & 1,069 & \\
Standar deviasi & 0,130 & 0,133 & $0,8-1,4$ \\
$\quad$ Rentang & $0,8-1,4$ & 0 \\
\hline
\end{tabular}

Keterangan: ${ }^{* *}$ ) perhitungan berdasarkan Uji Mann-Whitney

ini menunjukkan bahwa secara statistika tidak terdapat perbedaan yang signifikan pada jarak antara arteri femoralis dan saraf femoralis antara laki-laki dan perempuan $(\mathrm{p}=0,830$; Tabel 3).

\section{Pembahasan}

Pada hasil penelitian ini didapatkan ratarata tinggi badan 43 subjek penelitian lebih tinggi dari pada rata-rata tinggi badan orang Indonesia berdasarkan data antropometri, yaitu 163,2 cm untuk laki-laki dan 156,3 cm untuk perempuan. ${ }^{13}$ Gambaran indeks massa tubuh subjek penelitian termasuk kriteria indeks massa tubuh normal menurut World Health Organization (WHO).

Berdasarkan deskripsi data pada penelitian ini jarak arteri femoralis dengan saraf femoralis rata-rata pada laki-laki $1,075 \pm 0,13 \mathrm{~cm}$ dan jarak arteri femoralis dengan saraf femoralis rata-rata pada perempuan $1,069 \pm 0,13 \mathrm{~cm}$.

Hasil penelitian ini berbeda dengan penelitian pada tahun 2005 didapatkan jarak rata-rata antara saraf femoralis dan arteri femoralis adalah $1,87 \pm 0,1 \mathrm{~cm}^{9}$ Hasil pada penelitian pada tahun 2007 didapatkan jarak rata-rata adalah $0,94 \pm 0,18 \mathrm{~cm}^{14}$ Penelitian lain yang dipublikasikan tahun 2013 juga menunjukkan hasil yang berbeda didapatkan jarak rata-rata adalah $1,80 \pm 0,4 \mathrm{~cm}^{7}$

Hasil penelitian ini juga berbeda dengan hasil penelitian sebelumnya yang pernah dipublikasikan di Amerika Serikat, Taiwan, dan Inggris kemungkinan disebabkan perbedaan karakteristik umum subjek penelitian, yaitu variabel tinggi badan, berat badan, dan indeks massa tubuh
Penelitian lanjutan perlu dilakukan untuk mengetahui jarak saraf femoralis dengan arteri femoralis memakai pencitraan ultrasonografi pada orang dewasa dengan indeks massa tubuh yang lebih rendah atau lebih tinggi, kedalaman dan lebar saraf femoralis, serta korelasi jarak saraf femoralis dan arteri femoralis dengan berat badan, tinggi badan, serta indeks massa tubuh.

\section{Simpulan}

Jarak arteri femoralis rata-rata dengan saraf femoralis dari hasil penelitian ini adalah 1-1,2 $\mathrm{cm}$ lateral terhadap arteri femoralis untuk panduan penyuntikan blokade saraf femoralis.

\section{Daftar Pustaka}

1. Kasibhatla RD, Russon K. Femoral nerve blocks. J Perioper Prac. 2009;19(2):65-9.

2. Szucs S, Morau D, Iohom G. Femoral nerve blockade. Med Ultrason. 2010;12(2):13944.

3. Madison SJ, Ilfeld BM. Peripheral nerve blocks. Dalam: Butterworth JF, Mackey DC, Wasnick JD, penyunting. Morgan and Mikhail's clinical anesthesiology. Edisi ke-5. New York: McGraw-Hill; 2013. hlm. 975-1022.

4. Sharma S, Iorio R, Specht LM, Davies-Lepie S, Healy WL. Complications of femoral nerve block for total knee arthroplasty. Clin Orthop Relat Res. 2010;468:135-40.

5. Marhofer P, Harrop-Griffiths W, Kettner SC, Kirchmair L. Fifteen years of ultrasound guidance in regional anesthesia: Part $1 . \mathrm{Br}$ J Anaesth. 2010;104(5):538-46. 
6. Muhly WT, Orebaugh SL. Ultrasound evaluation of the anatomy of the vessel in relation to the femoral nerve at the femoral crease. Surg Radiol Anat. 2011;33:491-4.

7. Townsley P, Wiles MD, Moppet IK, Emery D. An ultrasound study of the anatomical position of the femoral nerve in patients with a fracture neck of femur. Int J Periop Ultrasound Appl Technol. 2013;2(1):14-8.

8. Sardesai AM, Iyer U. Nerve stimulation for peripheral nerve blockade. Anesthesia tutorial of the week [diunduh 12 September 2013]. Tersedia dari: http:// www.totw.anaesthesiologists.org.

9. Schulz-Stubner S, Henszel A, Hata JS. A new rule for femoral nerve blocks. Reg Anesth Pain Med. 2005;30(5):473-7.

10. Vloka JD, Hadzic A, Drobnik L, Ernest A, Reiss W, Thys DM. Anatomical landmarks for femoral nerve block: a comparison of four needle insertion sites. Anesth Analg.
1999;89:1467-70.

11. Gray AT. Ultrasound guidance for regional anesthesia. Dalam: Miller RD, penyunting. Miller's anesthesia. Edisi ke-7. United State of America: Churchill Livingstone; 2009. hlm. 1675-704.

12. Hadzic A. Hadzic's peripheral nerve blocks and anatomy for ultrasound guided regional anesthesia. Edisi ke-2. New York: McGraw Hill Medical; 2004.

13. Christian R, Nelwan. Antropometri Indonesia dan Hongkong. [diunduh 10 September 2014]. Tersedia dari: http:// dc415.4shared.com/doc/LTttku5F/ preview.html.

14. Hsu HT, LU IC, Chang YL, Wang FY, Kuo YW, Chiu SL, dkk. Lateral rotation of the lower extremity increase the distante between the femoral nerve and femoral artery: an ultrasonographic study. Kaohsiung J Med Sci. 2007;23(12):618-622 